\title{
The Highest Ever Reported Level of Carbohydrate Antigen 19-9: A Case Report
}

\author{
Hamoud Al-Khallaf ${ }^{\mathrm{a}, \mathrm{e}}$, Phillip J Monaghan ${ }^{\mathrm{b}}$, Ahmed Ourfalic, Mohamed Elsammak, \\ Cherrilyn Ambrosio ${ }^{\mathrm{c}}$, Ravinder Sodi ${ }^{\mathrm{d}}$, Abduljaleel Poovathumkadavil ${ }^{\mathrm{c}}$
}

\begin{abstract}
We present a case of adenocarcinoma of the tail of the pancreas with liver metastases expressing serum carbohydrate antigen 19-9 level of 19,516,020 U/ml. A review of the literature revealed that a concentration of this magnitude has not previously been reported for this tumor marker.
\end{abstract}

Keywords: Carbohydrate antigen 19-9; Highest reported level; Pancreatic tumor; Adenocarcinoma

\section{Introduction}

Initially found in colorectal cancer patients, carbohydrate antigen 19-9 (CA 19-9), discovered by Koprowski et al [1], has also been identified in patients with pancreatic, stomach, hepatocellular cancer, and bile duct cancer. Its use for screening asymptomatic populations has been hampered by a false-positive rate of $15 \%$ to $30 \%$ in patients with nonneoplastic diseases of the pancreas, liver, and biliary tract. In patients who have pancreatic cancer, the literature indi-

Manuscript accepted for publication February 4, 2011

aP.O. Box 15215 (MBC 035), King Fahad Specialist Hospital, Dammam 31444, Saudi Arabia

${ }^{\mathrm{b}}$ Department of Clinical Biochemistry, The Christie NHS Foundation Trust, Wilmslow Road, Withington, Manchester, M20 4BX, UK

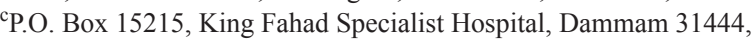
Saudi Arabia

${ }^{\mathrm{d} D e p a r t m e n t}$ of Clinical Biochemistry and Metabolic Medicine, Royal Liverpool and Broadgreen University Hospital, Liverpool, L7 8XP, UK

${ }^{\mathrm{e}}$ Corresponding author: Hamoud Al-Khallaf, drhhk@hotmail.com

doi:10.4021/jmc142w cates that higher levels of CA 19-9 tend to be associated with more advanced disease and that levels correlate with tumor burden. Consequently, CA 19-9 has been utilized as a prognostic marker for patients with all stages of the disease [2]. We present herein a case of adenocarcinoma of the tail of the pancreas with multiple liver metastases that lead to intrahepatic cholestasis. This patient had an extremely high level of CA 19-9 $(19,516,020 \mathrm{U} / \mathrm{ml})$ that has never been reported before.

\section{Case Report}

A 63-year-old Saudi male with type 2 diabetes mellitus (insulin-controlled) and hypertension on anti-hypertensive medications was admitted with anorexia and weight loss over the previous 4 months. The patient did not complain of abdominal pain and there was no history of smoking or alcoholism. On physical exam, his blood pressure was $127 / 80 \mathrm{mmHg}$, the pulse rate was $65 / \mathrm{min}$, temperature was $36.4^{\circ} \mathrm{C}$, and the respiration rate was $20 / \mathrm{min}$. His sclera were deeply icteric, lungs were clear, abdominal examination revealed non tender enlargement of the liver with positive shifting dullness.

Laboratory tests were as follows: Hemoglobin: $10.5 \mathrm{~g} / \mathrm{dl}$ (13.5 - 17.5), hematocrit: $32.4 \%$ (41\% - 53\%), white blood cell count $32.85 \times 10^{9} / \mathrm{L}\left(4.5 \times 10^{9}-11 \times 10^{9} / \mathrm{L}\right)$ and platelet count: $289 \times 10^{9}\left(150 \times 10^{9}-400 \times 10^{9}\right)$. Blood urea nitrogen: $11.3 \mathrm{mmol} / \mathrm{L}(2.7$ - 7.2), creatinine: $76 \mu \mathrm{mol} / \mathrm{L}(71-115)$, sodium: $122 \mathrm{mmol} / \mathrm{L}(135-147)$, potassium: $5.6 \mathrm{mmol} / \mathrm{L}$ (3.5 - 5.1), glucose: $11.2 \mathrm{mmol} / \mathrm{L}(3.9-6.1)$. Alanine aminotransferase level was $151 \mathrm{U} / \mathrm{L}$ (17 - 49), aspartate aminotransferase was $286 \mathrm{U} / \mathrm{L}(8$ - 38), alkaline phosphatase was $1251 \mathrm{U} / \mathrm{L}$ (54 - 144), gamma-glutamyl transferase $2188 \mathrm{U} / \mathrm{L}$ (15 - 85), total bilirubin was $123.4 \mu \mathrm{mol} / \mathrm{L}(4-21)$, and conjugated bilirubin was $113.0 \mu \mathrm{mol} / \mathrm{L}(0.8-3.3)$. Abdominal ultrasound examination revealed a $4.0 \times 5.0 \mathrm{~cm}$ mass in the tail of the pancreas. Multiple hypoechoic solid masses, the largest of which measured $7.0 \times 4.0 \mathrm{~cm}$, were detected in the enlarged liver. There was no intra or extra-hepatic duct dilatation and the gallbladder was contracted. Ascitic fluid was also detected.

The levels of tumor markers were as follows: alpha feto 


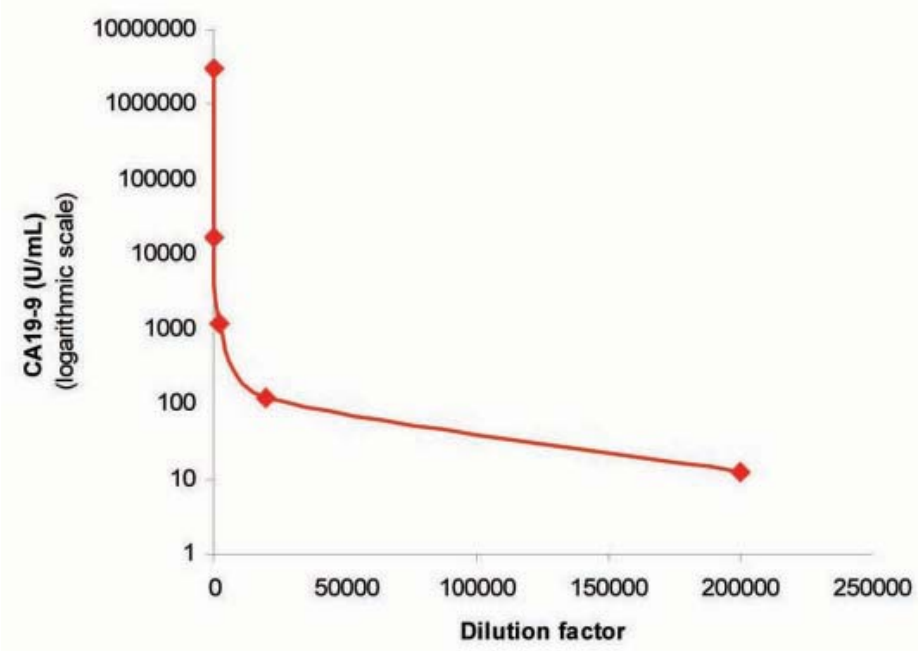

Figure 1. Curvilinear plot obtained by serial dilution of the sample.

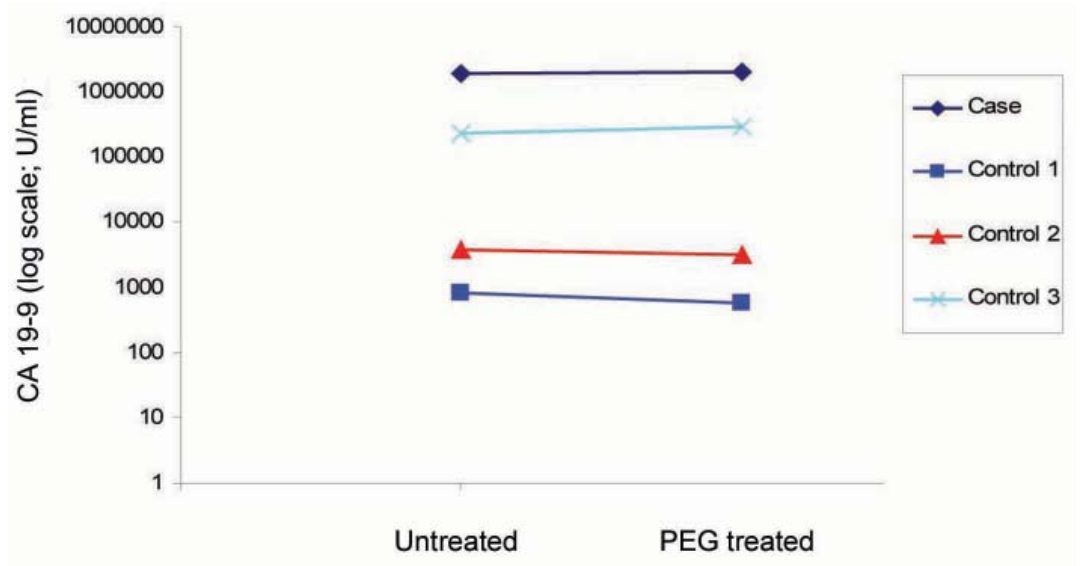

\begin{tabular}{|c|c|c|c|}
\hline Sample & Untreated & PEG & \%Recovery \\
\hline Case & 1978820 & 2028835 & 102.5 \\
\hline Control 1 & 794 & 585.9 & 73.8 \\
\hline Control 2 & 3721.8 & 3206.9 & 86.2 \\
\hline Control 3 & 237190 & 287435 & 121.2 \\
\hline
\end{tabular}

Figure 2. PEG precipitation study showing $102.5 \%$ recovery which is consistent with the 3 positive control samples that showed between $74 \%-121 \%$ recoveries.

protein (AFP): $5.3 \mathrm{ng} / \mathrm{ml}(1.1$ - 8.0), carcinoembryonic antigen (CEA): $25.2 \mu \mathrm{g} / \mathrm{L}(0$ - 5), and CA 19-9: 19,516,020 U/ $\mathrm{ml}(0$ - 37).

To exclude the possibility of interference as a cause of this extreme CA 19-9 elevation, we performed in our lab a repeat analysis on the same analyzer (Architect i2000), fol- lowed by re-analysis of the sample using heterophilic blocking tubes (HBT) with no change in the result. The sample was then sent to a Clinical Biochemistry lab in the UK where the sample was analyzed on a different immunoassay platform (Centaur $\mathrm{XP)}$ that gave a comparable result of $3,094,840 \mathrm{U} / \mathrm{ml}$. The sample was curvilinear on serial dilution (Fig. 1), which al- 


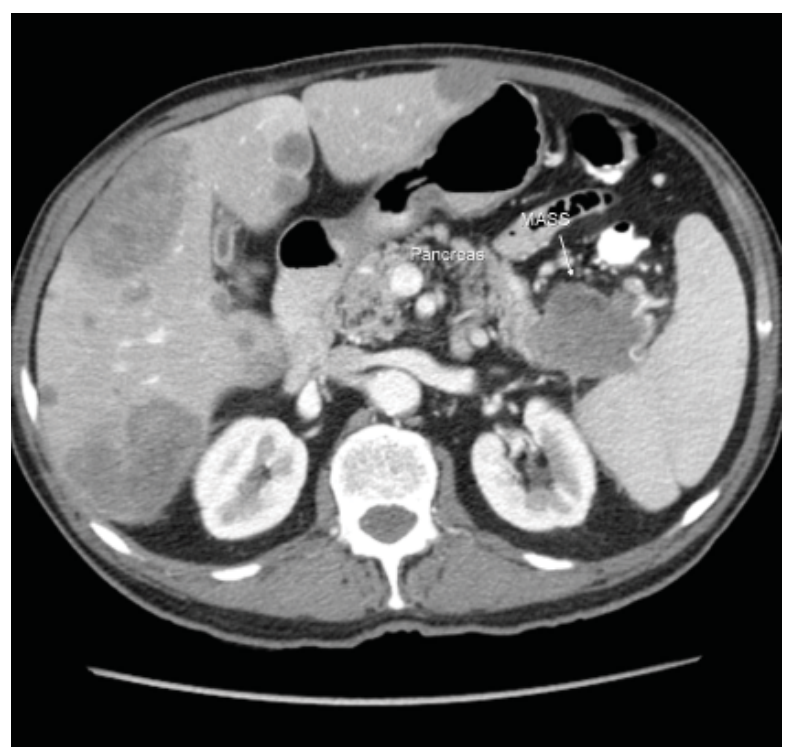

Figure 3. CT Axial showing primary tumor mass (MASS) in the tail of the pancreas and multiple liver metastases.

though did not exclude the presence of interference, did not suggest its presence. Finally, a mean recovery of $102 \%$ was obtained with polyethylene glycol (PEG) precipitation (Fig. 2) which excluded the presence of a macro-complex.

A computerized tomography (CT) scan of chest, abdomen, and pelvis was performed and confirmed the presence of multiple variable size hypo-dense lesions in both liver lobes with no other sign of extra-hepatic metastasis (Fig. 3, 4).

Ultrasound-guided biopsy was taken from the mass in the tail of the pancreas. Histopathological examination revealed moderately differentiated metastatic adenocarcinoma of the pancreas. Before the patient was referred to the Oncology department to determine the therapeutic approach, he developed spontaneous bacterial peritonitis that progressed to sepsis. Post liver biopsy, the patient developed bleeding secondary to fistula between the hepatic artery and portal vein which was embolized by interventional radiology. The patient was transferred to the intensive care unit where he passed away.

\section{Discussion}

CA 19-9 was initially proposed as a serologic marker for colorectal cancer [3]. Nowadays its use is not recommended for this purpose [3] and CA 19-9 serum concentration is mostly evaluated in patients with suspected pancreatic or biliary cancer, because of its presumed higher specificity in this setting [4]. Unfortunately, CA 19-9 levels have also been reported in other malignancies such as gastric and ovarian cancer and in different benign conditions like cys- tic fibrosis, hydronephrosis, and Hashimoto's thyroiditis [5]. Furthermore, elevated CA 19-9 serum concentration can be associated with several conditions producing reduced biliary drainage [6], especially in the presence of cholangitis [7]. It is generally believed that benign conditions cause only moderate elevations, while very high levels are mainly related to malignancies, consistent with the results of previous papers $[8,9]$. However, some researchers have published cases that documented extremely elevated CA 19-9 serum concentrations (up to $187,000 \mathrm{U} / \mathrm{ml}$ ) secondary to benign biliary obstruction that have rapidly normalized after recovery of biliary patency [10].

Production and secretion of CA 19-9 from malignant cells is considered to be responsible for the elevated serum CA 19-9 levels found in malignancy. The reason for the CA 19-9 elevation in acute cholangitis is not clear. Several mechanisms have been postulated, including: 1) leakage of condensed CA 19-9 due to biliary tract obstruction from the bile into blood circulation [4], 2) enhanced CA 19-9 production by irritated bile duct cells exposed to increased biliary pressure [11], 3) enhanced production of CA 19-9 in the bile duct epithelium and the mucosa of the gallbladder induced by the inflammatory process $[11], 4)$ the inflammatory cytokines produced in sepsis due to cholangitis may be a contributing factor [11].

CA 19-9 is measured by immunoassay methodology. It is well documented that immunoassay techniques are prone to interference [12]. Monaghan PJ et al 2009 published an elegant paper [13] documenting a case of elevated CA 19-9 due to the presence of a small molecular weight interferent.

After ruling out analytical interference, we concluded that the extremely high level of CA 19-9 in this patient was 


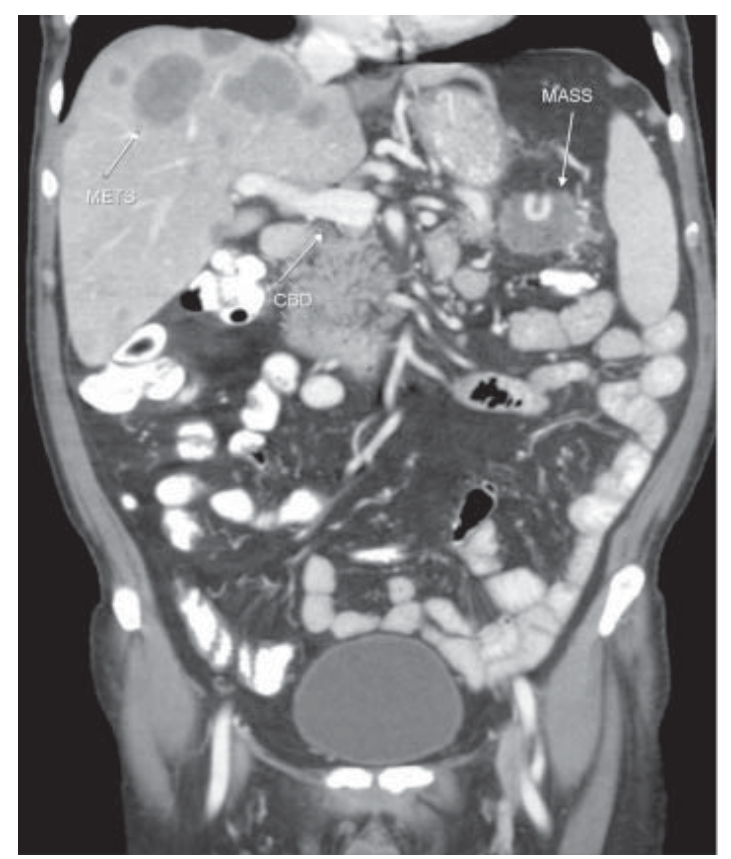

Figure 4. CT Coronal showing the tumor mass (MASS), liver metastases (METS), and common bile duct (CBD).

produced by two sources. The tumor cells of the primary tumor and liver metastases represent the first source. Secondly, the source which may have had the greatest contribution to CA 19-9 elevation, is the enhanced production of CA 19-9 from the biliary epithelial cells and decreased hepato-biliary clearance because of cholestasis. Cholestasis in this case was caused by the presence of multiple liver metastases and was augmented by the sepsis this patient endured secondary to the spontaneous bacterial peritonitis he had during his admission. Inflammatory cytokines released during sepsis could have stimulated the release of CA 19-9 from biliary epithelial cells and therefore played a part in elevating CA 19-9 level.

In this patient in particular, it is impossible to be certain of the main pathology causing this astonishingly elevated CA 19-9 level due to the multiple pathologies present, each of which is known to cause elevation in CA 19-9 serum concentration. However; since we found no case report with CA 19-9 levels higher than $100.000 \mathrm{U} / \mathrm{ml}$ in pancreatic malignancy, while a CA 19-9 level of $187,000 \mathrm{U} / \mathrm{ml}$ reported in simple choledocholithiasis [10], we can postulate that the presence of both of these conditions may have had a cumulative effect in producing the extremely high level of CA 19-9 in this patient.

It is clear from this case that CA 19-9 levels can reach several million international units per millilitre. Since knowing the exact level of a tumor marker is important, especially for prognosis and follow up, this case highlights the importance of determining the exact level of this tumor marker rather than just reporting it as "higher than the upper lin- ear limit". The exact level in this case was more than 16000 times the upper linear limit of our assay $(1200 \mathrm{U} / \mathrm{ml})$.

\section{Consent}

Written informed consent was obtained from the patient for publication of this case report and accompanying images. A copy of the written consent is available for review by the journal's Editor-in-Chief.

\section{Competing Interests}

We, the authors, declare that no competing interests exist.

\section{Authors' Contributions}

HK initiated the publication of this case, reviewed the literature and wrote the manuscript. PM undertook most of the analytical procedures pertaining to the sample CA 19-9 level and edited the manuscript. AO in addition to being the clinician in charge of the patient provided the relevant clinical data. MS made significant contribution by his planning and guidance. CA discovered the extremely high level of the tumor marker, brought it to our attention, and performed initial analytical measurements on the sample. RS provided consultation and guidance. AP provided patient's radiological images. All authors read and approved the final manuscript. 


\section{References}

1. Koprowski H, Steplewski Z, Mitchell K, Herlyn M, Herlyn D, Fuhrer P. Colorectal carcinoma antigens detected by hybridoma antibodies. Somatic Cell Genet 1979;5(6):957-971.

2. Katz MH, Moossa AR, Bouvet M. Serologic diagnosis of pancreatic cancer. In CA 19-9 in Neoadjuvant Chemoradiation Pancreatic Cancer. Edited by Von Hoff D, Evans DB, Hruban R. Sudbury, MA: Jones and Bartlett; 2005:235-250.

3. Bast RC, Jr., Ravdin P, Hayes DF, Bates S, Fritsche H, Jr., Jessup JM, Kemeny N, et al. 2000 update of recommendations for the use of tumor markers in breast and colorectal cancer: clinical practice guidelines of the American Society of Clinical Oncology. J Clin Oncol 2001;19(6):1865-1878.

4. Kim HJ, Kim MH, Myung SJ, Lim BC, Park ET, Yoo $\mathrm{KS}$, Seo DW, et al. A new strategy for the application of CA19-9 in the differentiation of pancreaticobiliary cancer: analysis using a receiver operating characteristic curve. Am J Gastroenterol 1999;94(7):1941-1946.

5. Parra JL, Kaplan S, Barkin JS. Elevated CA 19-9 caused by Hashimoto's thyroiditis: review of the benign causes of increased CA 19-9 level. Dig Dis Sci 2005;50(4):694695.

6. Katsanos KH, Kitsanou M, Christodoulou DK, Tsianos EV. High CA 19-9 levels in benign biliary tract diseases.
Report of four cases and review of the literature. Eur $\mathrm{J}$ Intern Med 2002;13(2):132-135.

7. Albert MB, Steinberg WM, Henry JP. Elevated serum levels of tumor marker CA19-9 in acute cholangitis. Dig Dis Sci 1988;33(10):1223-1225.

8. Patel AH, Harnois DM, Klee GG, LaRusso NF, Gores GJ. The utility of CA 19-9 in the diagnoses of cholangiocarcinoma in patients without primary sclerosing cholangitis. Am J Gastroenterol 2000;95(1):204-207.

9. Mann DV, Edwards R, Ho S, Lau WY, Glazer G. Elevated tumour marker CA19-9: clinical interpretation and influence of obstructive jaundice. Eur J Surg Oncol 2000;26(5):474-479.

10. Madonia S, Aragona E, Maisano S, Montalbano L, Olivo M, Rossi F, Restivo G, et al. CA 19-9 to rule out pancreatic or biliary cancer among patients with cholestasis: an unsuitable test? Dig Dis Sci 2007;52(4):1125-1127.

11. Marcouizos G, Ignatiadou E, Papanikolaou GE, Ziogas D, Fatouros M. Highly elevated serum levels of CA 19-9 in choledocholithiasis: a case report. Cases J 2009;2:6662.

12. Kricka LJ. Interferences in immunoassay--still a threat. Clin Chem 2000;46(8 Pt 1):1037-1038.

13. Monaghan PJ, Leonard MB, Neithercut WD, Raraty MG, Sodi R. False positive carbohydrate antigen 19-9 (CA19-9) results due to a low-molecular weight interference in an apparently healthy male. Clin Chim Acta 2009;406(1-2):41-44. 